\title{
Plankton patchiness in high-frequency internal waves
}

\author{
Cleridy E. Lennert-Cody*, Peter J. S. Franks
}

Marine Life Research Group, Scripps Institution of Oceanography, La Jolla, California 92093-0218, USA

\begin{abstract}
Internal waves are ubiquitous elements of the physical dynamics on continental shelves, yet their effect on the spatial distribution of planktonic organisms throughout the water column is not well understood. We explore the effects of high-frequency internal waves on the patch dynamics of swimming plankters using a 2-layered model with 2 idealized wave torms (linear and weakly nonlinear interfacial waves). Our analysis suggests that even weakly swimming planktonic organisms may experience internal wave-induced changes in concentration. We find that maximum increases in concentration occur over the trough of the wave, and that changes in concentration above the interface are opposite to those below the interface. To a first approximation, the magnitude of the changes in concentration increases linearly with the wave amplitude and the swimming proficiency of the plankters. Maximum increases in concentration occur within the upper layer and, for a given stratification, increase linearly with the wave amplitude. These maximurn increases in concentration are predicted to be less than twice the local background concentration. Such localized changes in the concentration of organisms should be ephemeral, lasting no longer than the wave period. Based on these results, we propose that coincident measurements of density (or temperature) and concentration of organisms through the water column can be used to determine the existence of 3 relationships that are consistent with internal wave-induced changes in the concentration of swimming plankters: (1) a relationship between along-isopycnal concentration anomalies and isopycnal depth that is out of phase above the pycnocline and in phase below the pycnocline (depth negative downwards), (2) a linear increase in the maximum along-isopycnal concentration anomalies with scaled isopycnal displacement amplitudes, and (3) maximum along-isopycnal concentration anomalies that are less than twice the background along-isopycnal concentration.
\end{abstract}

KEY WORDS: Plankton - Internal waves · Patchiness

\section{INTRODUCTION}

Long, narrow sea-surface slicks associated with internal waves are common features of exposed coastal environments. Such slicks, which may be accompanied by foam or debris, also have been shown to be associated with high concentrations of many types of planktonic organisms and small fishes (e.g. Zeldis \& Jillett 1982, Shanks 1983, Kingsford \& Choat 1986). Zeldis \& Jillett (1982) and Shanks (1983) were among the first to propose that organisms in these slicks are concentrated by currents associated with internal waves. While observations of slicks at the sea surface domi-

\footnotetext{
•E-mail: clennert@iattc.org
}

nate our knowledge of the effects of internal waves on patchiness of the plankton, recently published data suggest that these plankton patches may extend throughout the water column (Rogachev et al. 1996, Kushnir et al. 1997).

Consistent with the idea that internal waves can induce subsurface patchiness of swimming planktonic organisms, we observed localized increases in subsurface fluorescence that were coincident with highfrequency internal waves during a coastal bloom of Lingulodinium polyedrum (Fig. 1). Surface observations of dense phytoplankton blooms can show marked near-surface patchiness, often in long bands oriented parallel to shore (e.g. Ryther 1955, Peláez 1987, Franks 1997). Such near-surface banding has been attributed to internal wave-induced increases in the concentra- 


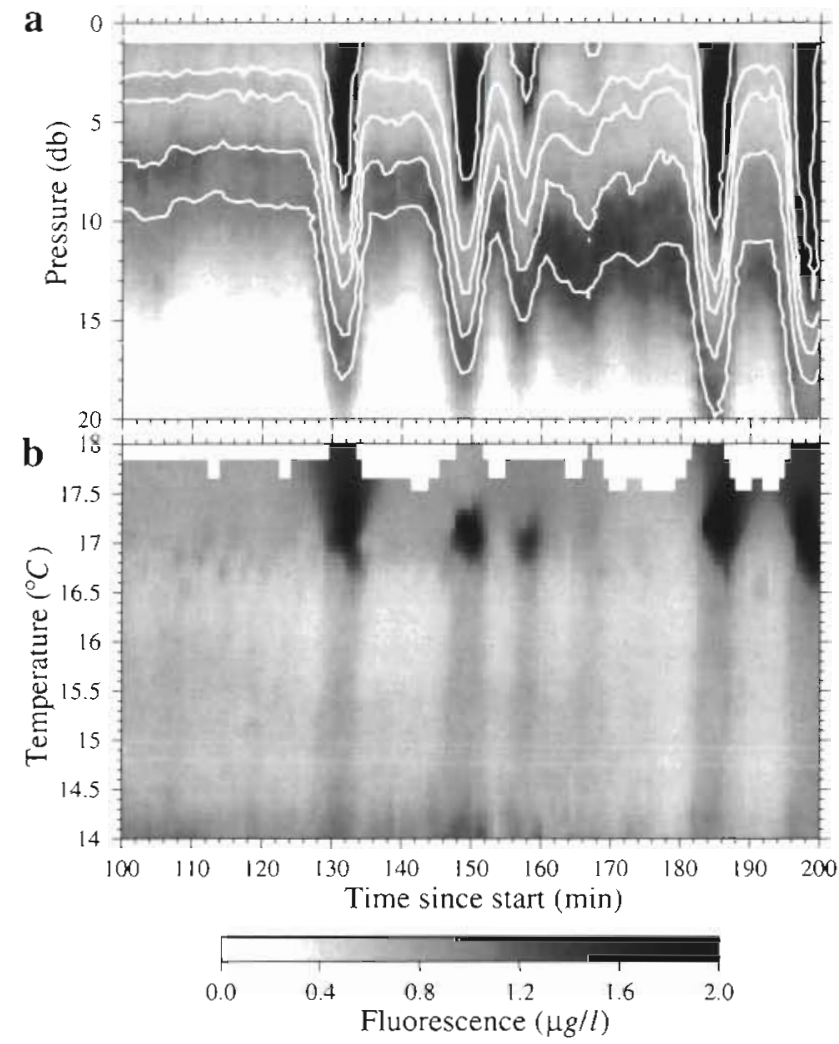

Fig. 1. (a) Chlorophyll fluorescence (gray scale; in $\mu \mathrm{g} \mathrm{l}^{-1}$ ) and temperature $\left(1^{\circ} \mathrm{C}\right.$ contours between 11 and $\left.17^{\circ} \mathrm{C}\right)$ for data collected with a profiling CTD/fluorometer instrument package during a bloom of Lingulodinium polyedrum on April 17, 1997 in $30 \mathrm{~m}$ of water off Mission Beach, California. Vertical sampling resolution is approximately $0.5 \mathrm{db}$; horizontal sampling resolution is approximately $1 \mathrm{~min}$. (b) The same fluorescence data plotted against temperature to show that the regions of high fluorescence in the wave troughs also appear as alongisotherm patches of fluorescence. Thus these patches are not solely due to vertical advection of vertical gradients of phytoplankton

tion of dinoflagellates (Iwasaki 1979, Kamykowski 1981, Franks 1997). Our observations suggest changes in the subsurface concentration of phytoplankton resulting from directed swimming (e.g. phototactic behavior) in the convergent flow field associated with internal waves. However, the plankton is notoriously heterogeneous, and many processes, both abiotic and biotic, contribute to the observed spatial and temporal patchiness (Haury et al. 1978, Mackas et al. 1985). Without knowledge of the patch structure of the plankton preceding internal wave events, it is unclear to what extent the observed pattern is solely attributable to internal waves. Models predict increases in concentration of near-surface organisms to occur over internal wave troughs (Franks 1997, Lamb 1997). However, the magnitude and vertical structure of internal waveinduced changes in concentration, and the depen- dence of these changes in concentration on wave characteristics, remain largely unexplored.

In preparation for an intensive field study measuring the effects of internal waves on patchiness of the plankton, we sought to develop quantitative, field-testable predictions of the effects of high-frequency internal waves on the concentration of planktonic organisms. We use a simple 2-layered model to derive equations describing interfacial wave-mediated changes in concentration of swimming organisms throughout the water column in high-frequency linear and weakly nonlinear waves from an Eulerian perspective. From these equations, we make predictions about the relationships between the wave form, and the location and magnitude of internal wave-induced patchiness of the plankton through the water column.

\section{MODELS}

We consider 2 simple models for interfacial waves propagating in the positive $x$ direction: a wave with small amplitude relative to the water depth (linear interfacial wave; Kinsman 1965) and a wave with larger amplitude relative to the water depth (weakly nonlinear interfacial wave; Osborne \& Burch 1980, Huthnance 1989, Ostrovsky \& Stepanyants 1989). These 2 wave profiles have been found to be good approximations to many observations of high-frequency internal waves in coastal waters. Our particular interest lies in internal waves with periods up to 10 s of minutes. We assume that the time scales of other sources of variability, both physical and biological (e.g. wind and tidal forcing, vertical migration), are much longer than the time scales of the internal wave events. For both wave profiles we assume that the water depth is shallow relative to the wave length, that the lower layer is thicker than the upper layer, and that the wave amplitude is less than the upper layer depth. In addition, we assume the background horizontal current to be zero. For the 2-dimensional models that follow, the upper and lower layers are designated with subscripts $u$ and $l$, respectively, and depth $z$ is measured positive downward with 0 at the surface. (Thus positive vertical speeds are directed downward.) We denote horizontal velocity by $u$ and vertical velocity by $w$.

\section{Linear wave}

A high-frequency, linear interfacial wave with amplitude $a$ is characterized as a sinusoidal disturbance of the interface and can be modeled as (Fig. 2a)

$$
\eta=a \sin \left[2 \pi\left(x-c_{0} t\right) / L\right]
$$


where $\eta$ is the displacement of the interface from its undisturbed position at horizontal location $x$ and time $t$, $L$ is the wavelength, and $c_{0}$ is the speed at which crests and troughs propagate (the phase speed). In shallow water, internal waves with amplitudes that are 10 times less than the water depth are typically considered linear internal waves. Within each layer the horizontal current reverses direction as the wave passes, and at any point along the wave, horizontal velocities reverse direction across the interface (Fig. 3a). Vertical velocities, which are maximal at the interface, are directed downwards in both layers as the trough approaches and upwards as the crest approaches. Given a density difference between the 2 layers of $0.001 \mathrm{~kg} \mathrm{~m}^{-3}$, a lower-layer density of $1.025 \mathrm{~kg} \mathrm{~m}^{-3}$, upper- and lower-layer thicknesses of 10 and $20 \mathrm{~m}$, and a wave amplitude of $1 \mathrm{~m}$, the maximum absolute hori-
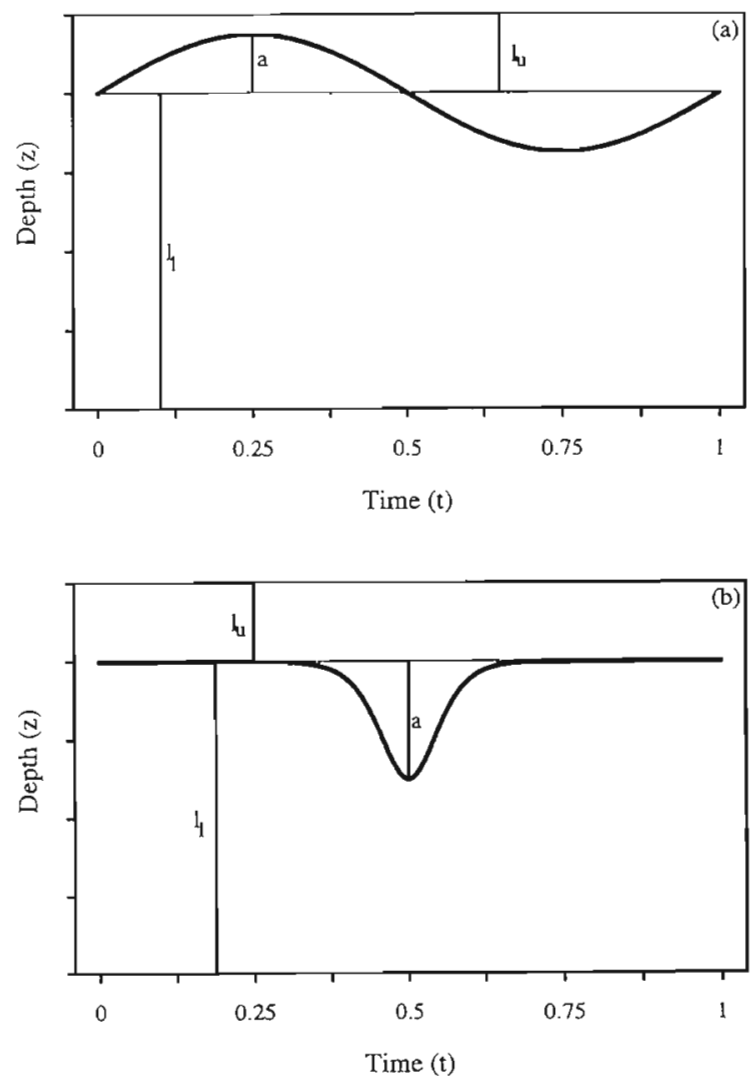

Fig. 2. (a) Variation in the interface depth over time due to the passage of a linear interfacial wave (Eq. 1), as viewed from a fixed horizontal location. Depth $(z)$ is shown on the vertical axis and is positive downwards; time $(t)$, shown on the horizontal axis, ranges between 0.0 and 1 wave period. The wave amplitude has been accentuated to show the wave form. $l_{u}=$ undisturbed depth of the upper layer, $l_{1}=$ undisturbed depth of the lower layer, and $a=$ amplitude of the wave. (b) Variation in the interface depth over time due to the passage of a weakly nonlinear interfacial wave (Eq. 2), as viewed from a fixed horizontal location
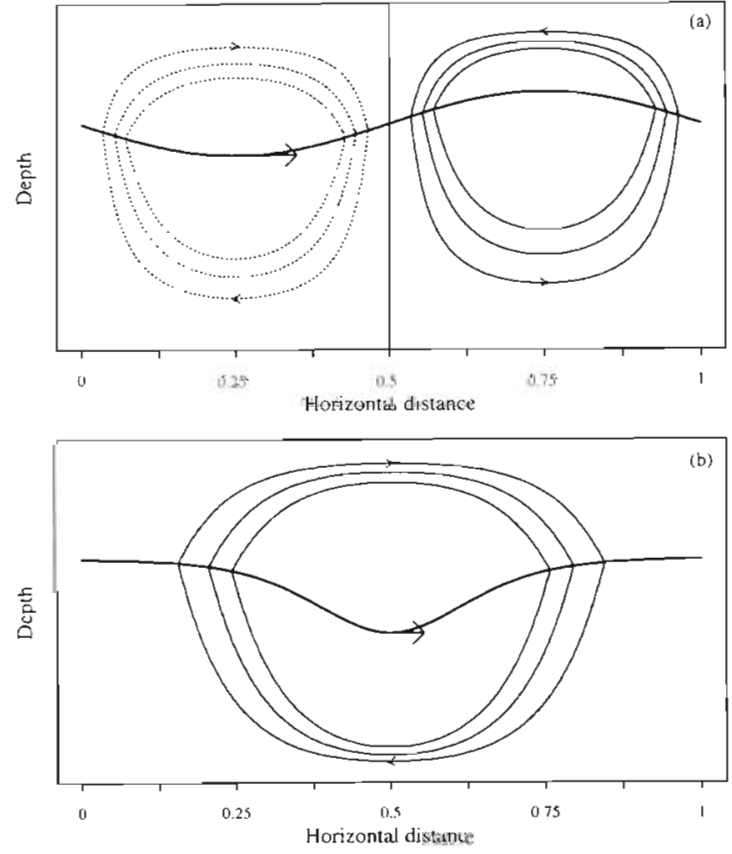

Fig. 3. Instantaneous stream functions for (a) a linear interfacial wave (Eq. 1), and (b) a weakly nonlinear interfacial wave (Eq. 2), both propagating to the right. Note that within each layer, the horizontal velocities reverse direction over the length of the linear wave, but not over the length of the nonlinear wave. Wave amplitudes have been accentuated to show the wave form

zontal and vertical velocities for a wave with a wave length of $300 \mathrm{~m}$ would be approximately $3 \mathrm{~cm} \mathrm{~s}^{-1}$ and $1 \mathrm{~mm} \mathrm{~s}^{-1}$, respectively.

\section{Weakly nonlinear wave}

A high-frequency, weakly nonlinear interfacial wave in this 2-layer setting may take the form of an isolated depression of the interface and can be modeled as (Fig. 2b)

$$
\eta=a \operatorname{sech}^{2}[(x-c t) / L]
$$

where $c$ is the nonlinear phase speed $c>c_{0}$. Depending on the water depth, high-frequency large-amplitude internal waves in coastal waters may have amplitudes of up to $10 \mathrm{~s}$ of meters. For a given stratification, the difference between $c_{0}$ and $c_{\text {, }}$ and between the maximum linear and nonlinear interfacial wave velocities, increases with $a$. In contrast to the linear interfacial wave, the horizontal currents associated with the weakly nonlinear wave do not reverse direction over the length of the wave (compare Fig. 3a to b). Given a wave amplitude of $5 \mathrm{~m}$ in our hypothetical 2-layer ocean, maximum absolute horizontal and vertical velocities associated with this wave would be approximately $16 \mathrm{~cm} \mathrm{~s}^{-1}$ and $10 \mathrm{~mm} \mathrm{~s}^{-1}$, respectively. 


\section{Swimming behavior}

Many taxa of planktonic organisms are motile. Vertical environmental gradients in the ocean are typically orders of magnitude greater than the horizontal environmental gradients and thus swimming typically has a strong vertical component, but is largely undirected horizontally (though see Shanks 1995). Maximum speeds for many protists measured in the laboratory are less than $0.5 \mathrm{~mm} \mathrm{~s}^{-1}$ (Bauerfeind et al. 1986, Kamykowski et al. 1992, Buskey et al. 1993), whereas maximum speeds for many species of invertebrate larvae and copepods are on. the order of several millimeters per second (Chia et al. 1984, Greene \& Landry 1985, Tiselius 1992). Plankters such as euphausids and some species of crustacean larvae have maximum swimming speeds in excess of several centimeters per second (Chia et al. 1984, Price 1989). Laboratory studies suggest that changes in environmental characteristics such as light and temperature may lead to changes in the direction and speed of swimming (Kamykowski \& McCollum 1986, Kamykowski et al. 1988, Jonsson 1989, Young 1995). On short time scales, the swimming response has been found to be relatively rapid (Jonsson 1989). Directed vertical swimming in dinoflagellates, ciliates and many forms of marine invertebrate larvae has been proposed to result from phototactic, geotactic, or geotactic-like mechanisms (Cullen \& Horrigan 1981, Jonsson 1989, Young 1995). Rheotactic and barokinetic swimming responses also have been observed in some taxa of marine invertebrate larvae (Young 1995). Thus, we conclude that, although many members of the plankton may not have swimming speeds comparable to velocities associated with internal waves, the potential exists among many taxa for directed and variable swimming.

We will assume that plankters swim only vertically, in opposition to the physical flow. This does not require that the organisms are able to sense the surrounding flow field. A phototactic response to deviations from a preferred light regime could produce a similar swimming behavior. In what follows, we will refer to the vertical velocities associated with the interfacial wave in the upper and lower layers, $w_{u}$ and $w_{1}$, collectively as $w$. We assume that the swimming speed of the organisms depends on the rate at which they are being disturbed, i.e. on the magnitude of $w$. That is, a wave with a larger amplitude that leads to more abrupt changes in the plankters' immediate environment (e.g. illumination) elicits a faster swimming response than a wave with a smaller amplitude. Thus, we model the swimming velocity of the planktonic organisms, $w_{\mathrm{s}}$, as

$$
w_{\mathrm{s}}=-\alpha w
$$

where $\alpha$ is the swimming proficiency of the organisms, $0<\alpha \leq 1$. For $\alpha=1, w_{s}=-w$, and the swimming behav- ior is perfectly depth-keeping. Because $w$ is proportional to $z$ for both types of interfacial wave models (at fixed $x$ and $t$ ), the maximum absolute swimming speed given by Eq. (3) is 0 at the surface, increases linearly with depth to the interface and then decreases linearly with depth to 0 at the bottom. We constrain $\left|w_{\mathrm{s}}\right| \leq|w|$ because we are interested in the effect of internal waves on the concentration of organisms residing within a particular region of the water column, as opposed to the effect on organisms swiftly migrating through the water column.

\section{Concentration of planktonic organisms}

Assuming that the concentration of planktonic organisms is a conservative quantity (i.e. no growth or losses occur), the equation governing temporal and spatial changes in concentration of the plankters in the upper layer, $C_{u}(x, z, t)$, is given by

$$
\partial C_{\mathrm{u}} / \partial t=-\left\{\partial / \partial x\left(u_{\mathrm{u}} C_{\mathrm{u}}\right)+\partial / \partial z\left[\left(w_{\mathrm{u}}+w_{\mathrm{s}}\right) C_{\mathrm{u}}\right]\right\}
$$

where $w_{\mathrm{s}}$ is given by Eq. (3), and $u_{\mathrm{u}}$ and $w_{\mathrm{u}}$ are the horizontal and vertical velocities associated with the interfacial wave. We express $C_{\mathrm{u}}(x, z, t)$ as the sum of a homogeneous background concentration $C$ and a perturbation concentration $C^{\prime}$. That is,

$$
C_{u}(x, z, t)=C+C^{\prime}(x, z, t)
$$

We will assume that $C^{\prime}$ and spatial gradients in $C^{\prime}$ are very small relative to $C$ and thus have negligible effects on temporal changes in $C_{u}$. Substituting Eq. (5) into Eq. (4), evaluating derivatives and eliminating terms involving $C^{\prime}$, we approximate Eq. (4) by

$$
\partial C_{\mathrm{u}} / \partial t \cong-C\left[\partial u_{\mathrm{u}} / \partial x+\partial / \partial z\left(w_{\mathrm{u}}+w_{\mathrm{s}}\right)\right]
$$

Thus Eq. (6) gives an expression for temporal changes in $C_{\mathrm{u}}$ under the assumption that the dominant forcing involves spatial gradients in the velocity field (convergences and divergences) acting on $C$. If the organisms are completely passive (i.e. $w_{\mathrm{s}} \equiv 0$ ), then, in the absence of spatial gradients in $C^{\prime}$, it can be shown from Eq. (4) that $\partial C_{\mathrm{u}} / \partial t=0$ due to the incompressibility of water (i.e. $\partial u_{\mathrm{u}} / \partial x+\partial w_{\mathrm{u}} / \partial z=0$ ). Thus there is no accumulation of passive planktonic organisms. We will assume that, to a first approximation, there is no exchange of organisms between the upper and lower layers and thus we consider the concentration of organisms in the 2 layers separately. Similar calculations lead to an expression equivalent to Eq. (6) for the lower layer.

Approximations to the horizontal and vertical velocities of the fluid are obtained from

$$
u_{\mathrm{u}}=c_{0} \eta / I_{\mathrm{u}} \text { and } w_{\mathrm{u}}=-\left(c_{0} z / I_{\mathrm{u}}\right) \partial \eta / \partial \mathrm{x}
$$

for the upper layer, and 


$$
u_{1}=-c_{0} \eta / l_{1} \text { and } w_{i}=-\left(c_{0}(d-z) / l_{1}\right) \partial \eta / \partial x
$$

for the lower layer, where $d=l_{1}+l_{\mathrm{u}}$, and the wave profiles, $\eta$, are given by Eqs. (1) \& (2) (Kinsman 1965, Osborne \& Burch 1980, Provenzale et al. 1990). Predictions of concentration are obtained by substituting expressions derived from Eqs. (7) \& (8) and Eq. (3) into Eq. (6) (or equivalent for the lower layer), and integrating with respect to time.

\section{RESULTS}

Low-order Eulerian predictions of interfacial waveinduced changes in the concentration of swimming plankters are given by

$$
C_{u}(t)=C\left[1-\alpha\left(a / l_{u}\right) \eta^{*}\right]
$$

for any depth within the upper layer, and

$$
C_{1}(t)=C\left[1+\alpha\left(a / h_{1}\right) \eta^{*}\right]
$$

for any depth within the lower layer. $\eta^{\bullet}$ is the wave profile (Eqs. 1 or 2), scaled by the wave amplitude: for the linear interfacial wave, $\eta^{*}=\sin \left(2 \pi c_{0} t / L\right)$, and for the weakly nonlinear interfacial wave, $\eta^{*}=-\operatorname{sech}^{2}(c t / L)$.

It follows from Eqs. (9) \& (10) that any swimming organisms with behaviors approximated by Eq. (3) will experience internal wave-induced fluctuations in concentration. Regardless of the wave profile, we would expect that, for a given stratification and a given swimming proficiency, the magnitude of the internal waveinduced changes in concentration should increase linearly with the wave amplitude. On the other hand, for a given stratification and wave amplitude, we would predict greater changes in concentration for fast swimmers than for slow swimmers, with maximal changes in concentration occurring for organisms that are perfectly depth-keeping $(\alpha=1$ in Eq. 3$)$. These changes in concentration are ephemeral, persisting no longer than the wave period.

Independent of the wave profile, these simple models predict that the response of concentration to internal wave forcing should vary through the water column due to the reversal of the vertical gradient of vertical displacement across the interface. For example, within the upper layer as the trough of the wave approaches, concentration increases to a maximum over the trough of the wave (Eq. 9, Figs. 4 \& 5), as was noted by Franks (1997) and Lamb (1997) for surfacetrapped organisms. However, within the lower layer as the trough approaches, concentration decreases from the background level (Eq. 10) to a minimum under the wave trough. Because the upper layer is thinner than the lower layer, we would expect the greatest changes in concentration to occur within the upper layer.
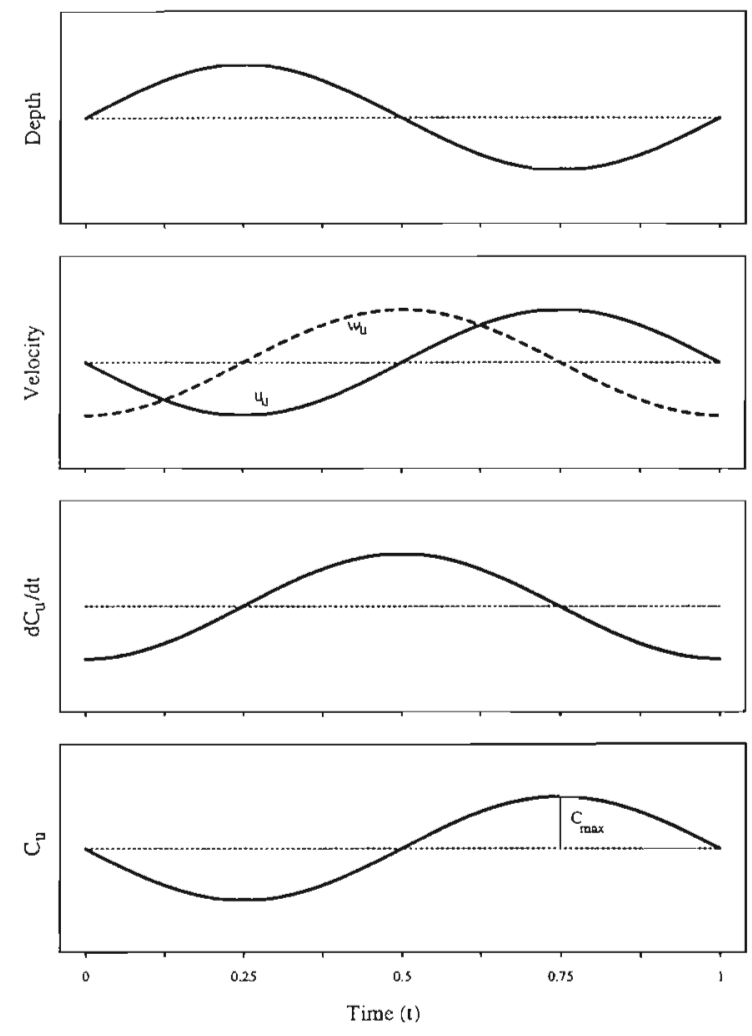

Fig. 4. Variation in the depth of the interface, horizontal and vertical velocities $\left(u_{\mathrm{u}}\right.$ and $w_{\mathrm{u}}$ i positive vertical velocities are directed downwards), rate of change of concentration of organisms $\left(\partial C_{u} / \partial t\right)$, and concentration of organisms $\left(C_{u} i\right.$ Eq. 9) induced by the passage of a linear interfacial wave, as viewed from a fixed horizontal location for any depth within the upper layer

The maximum predicted concentration of planktonic organisms is given by (from Eq. 9)

$$
C_{\max }=C\left[1+\alpha\left(a / l_{\mathrm{u}}\right)\right]
$$

Thus, to lowest order, the maximum concentration is independent of the wave profile. For a given stratification, $C_{\max }$ increases linearly with the wave amplitude, the rate depending on the swimming proficiency of the plankters (Fig. 6). Regardless of the swimming proficiency, the maximal predicted concentration is less than twice the background concentration (i.e. $<2 C$ ).

\section{DISCUSSION}

We have used a 2-layered model with 2 idealized wave forms to predict changes in the concentration of planktonic organisms swimming in high-frequency internal waves from an Eulerian perspective. Our analysis suggests that even weakly swimming plank- 

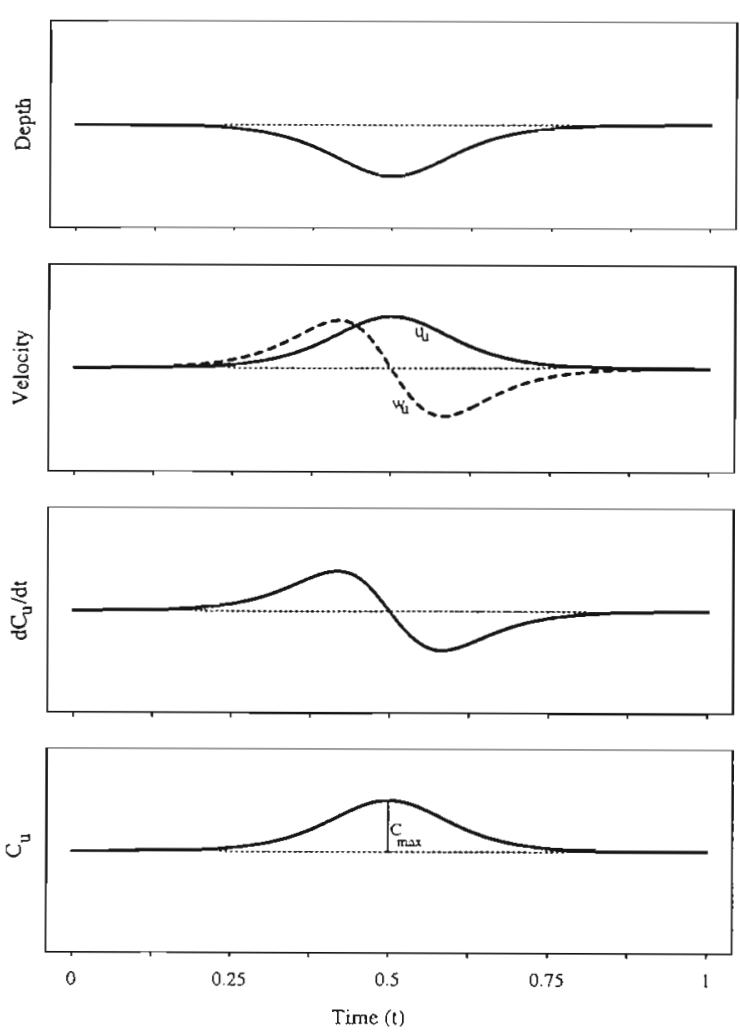

Fig. 5. Variation in the depth of the interface, horizontal and vertical velocities $\left(u_{\mathrm{u}}\right.$ and $w_{\mathrm{u}}$; positive vertical velocities are directed downwards), time rate of change of concentration of organisms $\left(\partial C_{\mathrm{u}} / \partial t\right)$, and concentration of organisms $\left(C_{\mathrm{u}}\right.$; Eq. 9) induced by the passage of a weakly nonlinear interfacial wave, as viewed from a fixed horizontal location for any depth within the upper layer

ters may experience internal wave-induced changes in concentration. To a first approximation we find that

- maximum increases in concentration occur over the trough of the wave,

- changes in concentration above the pycnocline are opposite to those below the pycnocline (Eqs. 9 \& 10),

- changes in concentration increase linearly with the wave amplitude and the swimming proficiency of the organisms (Eqs. 9 \& 10),

- maximum increases in concentration occur within the upper layer and increase linearly with the wave amplitude for a given stratification (Eq. 11; Fig. 6), and

- maximum increases in concentration are predicted to be less than twice the local background concentration (Eq. 11).

The results of these simple models suggest several field-testable relationships that would be consistent with high-frequency internal wave-induced changes in the concentration of planktonic organisms in an approximately 2-layer coastal environment. First, our models predict the maxima in concentration to occur over the trough of the wave within the upper part of the water column. That is, changes in concentration of planktonic organisms within the upper layer are predicted to be $180^{\circ}$ out of phase with displacements of the pycnocline (depth negative downwards). Within the lower layer, a minimum in concentration is predicted to occur under the trough of the wave, and changes in concentration are in phase with displacements of the pycnocline. Second, our results suggest that, for a given stratification, there should be a linear relationship between local maximum concentration anomalies (i.e. $\max [(\boldsymbol{C}-C) / C])$ and the scaled isopycnal displacement amplitude (i.e. $a / l_{\mathrm{u}}$ or $a / l_{1}$ ). Finally, local maximum concentration anomalies, which are predicted to occur within the upper layer, should not exceed twice the local background concentration.

Given the inherent heterogeneity in the distributions of planktonic organisms, internal wave-induced changes in concentration are perhaps best studied using alongisopycnal (or along-isotherm) concentration anomalies If organisms behave completely passively, then on short time scales we would expect the organisms to be advected with the water, similar to temperature. That is, along an isopycnal, no changes in concentration would be expected to occur. Studying changes in concentration along isopycnals avoids the potential for misinterpretation of the vertical advection of vertical gradients in concentration by internal waves as local-

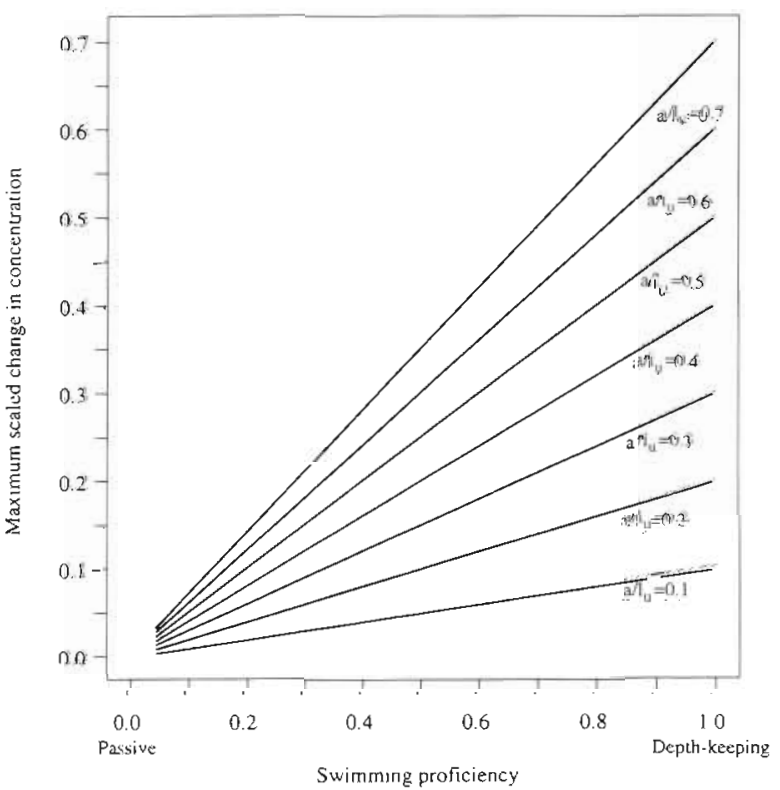

Fig. 6. Maximum scaled increase in concentration $\left(\left[\left\{\boldsymbol{C}_{\max }\right.\right.\right.$ - C//C], from Eq. 11; $y$-axis) versus swimming proficiency $\left(\alpha_{i} x\right.$-axis $)$ for scaled wave amplitudes of 0.10 (e.g. $\mathrm{a} / \mathrm{l}_{\mathrm{u}}=$ $1 \mathrm{~m} / 10 \mathrm{~m}$; lower-most line) to 0.70 (e.g. $a / \mathrm{l}_{\mathrm{u}}=7 \mathrm{~m} / 10 \mathrm{~m}$ i upper-most line) 
ized changes in concentration due to swimming in a convergent flow field. When sampled at a fixed depth, along-isopycnal patches in concentration and vertical gradients in concentration, which are constant along isopycnals, will be indistinguishable. However, when sampled along an isopycnal, only along-isopycnal patchiness should show variation (Fig. 1).

The changes in concentration described by the Eqs. (9) \& (10) are specific manifestations of the more general phenomenon of internal wave strain. Wave strain can be viewed as the vertical separation of the isopycnals; as a wave trough passes, the isopycnals are stretched away from the surface, producing a strain. It is this pulling apart, combined with vertical swimming of the plankton, that leads to changes in concentration in the strained region. Such strains do not occur just in the simple 2-layered models we explored here, but can also occur within continuously stratified fluids. Indeed, adjacent isopycnals do not have to be near the surface; they merely have to separate vertically to accumulate (or disperse) swimming organisms. Thus this mechanism may be prevalent in the interior of the ocean, as well as in coastal zones.

The physical characteristics of our models are to lowest order an adequate approximation of the marine environment in many areas of the world's exposed coastal zones; however, variability in thermal stratification and wave characteristics not addressed in our simple models may have effects on internal wavemediated changes in concentration not predicted by our analyses. For example, depth-dependence of the horizontal velocity would likely lead to different estimates of the magnitude of internal wave-induced changes in concentration through the water column, an aspect not addressed in our model. Incorporation of horizontal velocity shear and continuous stratification into a model for internal wave-mediated changes in the concentration of planktonic organisms would allow for more realistic descriptions of the effects of coastal physical forcing on patchiness of the plankton.

Vertical swimming that is less directed, particularly in the region of convergence, should lead to less of an increase in concentration than predicted by Eq. (11). Given the diverse swimming behaviors of planktonic organisms (e.g. Kamykowski et al. 1992, Buskey et al. 1993), it would be useful to incorporate more general swimming behaviors into a numerical simulation of internal wave dynamics to explore the effects on $C_{\max }$. Such a numerical model could accommodate upward swimming punctuated by periods of sinking, and horizontal swimming. This type of model would have the added benefit that the concentration effects would not be limited to the low-order specifications we have used to arrive at an analytical solution for the Eulerian perspective. Our prediction for the maximal value of
$C_{\max }$ may not be applicable to organisms migrating swiftly through the water column. Continuous upward swimming at speeds greater than the physical flow would result in a net migration of organisms to the surface where previous studies have demonstrated that they will accumulate over the trough of the wave (Franks 1997. Lamb 1997). Such behavior could clearly lead to increases in concentration at the surface in excess of $2 C$.

Internal wave-mediated changes in concentration of planktonic organisms have implications for the spatial structure and retention of phytoplankton blooms in coastal waters. Internal waves are commonly observed on continental shelves when stratification is strongest, also a time of blooms of dinoflagellates in many areas. Our results support the idea that high-frequency internal waves are a potential mechanism for producing along-isopycnal heterogeneity in the spatial distributions of such blooms on the scales of 100 s of meters in the cross-shore direction, and potentially kilometers in the alongshore direction. Such banding is visible in satellite images (e.g. Peláez 1987) and this spatial patchiness may provide a means of locating blooms of toxic dinoflagellates on global scales. The potential for high-frequency large-amplitude internal waves to transport planktonic organisms cross-shelf (Lamb 1997) suggests that these waves may contribute to the retention of blooms of phytoplankton in the nearshore environment and may play a role in the episodic introduction of toxic phytoplankton cells into regions where they will be consumed by benthic filter-feeding organisms. Cross-shelf transport of meroplankton by internal waves has been proposed as one of several mechanisms potentially contributing to the retention of larvae of nearshore benthic organisms in coastal habitats (Shanks 1983, Shanks \& Wright 1987, Pineda 1991, Pineda 1994).

Given the ephemeral nature of high-frequency internal wave-mediated changes in the concentration of planktonic organisms, it would be anticipated that such changes are of only localized biological importance in the plankton. High concentrations of potential food (e.g. dinoflagellates, ciliates or smaller copepods) may be utilized by other planktonic organisms (e.g. larger species of copepods or larval fishes) that are in the immediate vicinity and can swim faster than the physical flow. For example, some species of herbivorous copepods have been shown to have behavioral responses to patchy food environments (Tiselius 1992) and are generally considered to be more motile than their phytoplankton prey. On the other hand, locally increased concentrations of dinoflagellates (Smayda 1997) or ciliates might be self-beneficial by increasing the success of sexual reproduction. Although internal wave events are ephemeral, high-frequency large- 
amplitude internal waves have often been observed to occur in packets and sometimes at particular phases of the internal tide (e.g. Holloway 1987), suggesting that while ephemeral, some internal wave-mediated changes in concentration might be predictable.

Acknowledgements. The authors wish to thank Myrl Hendershott, Kevin Lamb, Michael Mullin and 3 anonymous reviewers for comments and suggestions that greatly improved this manuscript.

\section{LITERATURE CITED}

Bauerfeind E, Elbrächter $M$, Steiner R, Throndsen J (1986) Application of Laser Doppler Spectroscopy (LDS) in determining swimming velocities of motile phytoplankton. Mar Biol 93:323-327

Buskey EJ, Coulter C, Strom S (1993) Locomotory patterns of microzooplankton: potential effects on food selectivity of larval fish. Bull Mar Sci 53:29-43

Chia FS, Buckland-Nicks J, Young CM (1984) Locomotion of marine invertebrate larvae: a review. Can J Zool 62 $1205-1222$

Cullen JJ, Horrigan SG (1981) Effects of nitrate on the diurnal vertical migration, carbon to nitrogen ratio, and the photosynthetic capacity of the dinoflagellate Gymnodinium splendens. Mar Biol 62:81-89

Franks PJS (1997) Spatial pattern in dense algal blooms Limnol Oceanogr 42:1297-1305

Greene CH, Landry MR (1985) Patterns of prey selection in the cruising calanoid predator Euchaeta elongata. Ecology $66: 1408-1416$

Haury LR, McGowan JA, Wiebe PH (1978) Patterns and processes in the time-space scales of plankton distributions. In: Steele JH (ed) Spatial pattern in plankton communities. Plenum Press, New York, p 277-327

Holloway PE (1987) Internal hydraulic jumps and solitons at a shelf break region on the Australian North West Shelf J Geophys Res 92:5405-5416

Huthnance JM (1989) Internal tides and waves near the continental shelf edge. Geophys Astrophys Fluid Dynam 48:81-106

Iwasaki H (1979) Physiological ecology of red tide flagellates. In: Levandowsky M. Hutner SH (eds) Biochemistry and Physiology of Protozoa. Academic Press, New York, p $357-393$

Jonsson PR (1989) Vertical distribution of planktonic ciliates - an experimental analysis of swimming behaviour. Mar Ecol Prog Ser 52:39-53

Kamykowski D (1981) The simulation of a southern California red tide using characteristics of a simultaneously-measured internal wave field. Ecol Model 12:253-265

Kamykowski D, McCollum SA (1986) The temperature acclimatized swimming speed of selected marine dinoflagellates. J Plankton Res 8:275-287

Kamykowski D, McCollum SA, Kirkpatrick GJ (1988) Observations and a model concerning the translational velocity of a photosynthetic marine dinoflagellate under variable environmental conditions. Limnol Oceanogr 33:66-78

Kamykowski D, Reed RE, Kirkpatrick GJ (1992) Comparison of sinking velocity, swimming velocity, rotation and path characteristics among six marine dinoflagellate species. Mar Biol 113:319-328

Editorial responsibility: Thomas Kiørboe (Contributing Editor). Charlottenlund, Denmark
Kingsford MJ, Choat JH (1986) Influence of surface slicks on the distribution and onshore movements of small fish. Mar Biol 91:161-171

Kinsman B (1965) Wind waves: their generation and propagation on the ocean surface. Prentice Hall, Englewood Cliffs, NJ

Kushnir VM, Tokarev YuN, Williams R, Piontkovski SA, Evstigneev PV (1997) Spatial heterogeneity of the bioluminescence field of the tropical Atlantic Ocean and its relationship with internal waves. Mar Ecol Prog Ser 160:1-11

Lamb KG (1997) Particle transport by nonbreaking, solitary internal waves. J Geophys Res 102:18641-18660

Mackas DL, Denman KL, Abbott MR (1985) Plankton patchiness: biology in the physical vernacular. Bull Mar Sci 37: $652-674$

Osborne AR, Burch TL (1980) Internal solitons in the Andaman Sea. Science 208:451-460

Ostrovsky LA, Stepanyants YuA (1989) Do internal solitons exist in the ocean? Rev Geophys 27:293-310

Peláez J (1987) Satellite images of a 'red tide' episode off southern California. Oceanol Acta 10:403-410

Pineda J (1991) Predictable upwelling and the shoreward transport of planktonic larvae by internal tidal bores. Science 253:548-551

Pineda J (1994) Internal tidal bores in the nearshore: warmwater fronts, seaward gravity currents and the onshore transport of neustonic larvae. J Mar Res 52:427-458

Price HJ (1989) Swimming behavior of krill in response to algal patches: a mesocosm study. Limnol Oceanogr 34: $649-659$

Provenzale A, Osborne AR, Boffetta G, Serio M (1990) Particle orbits from the Lagrangian and the Eulerian Korteweg-de Vries equations. Phys Fluids 2:866-869

Rogachev KA, Salomatin AS, Carmack EC (1996) Concentration of pelagic organisms at mesoscale fronts in the western subarctic Pacific: small fish on long waves. Fish Oceanogr 5:153-162

Ryther JH (1955) Ecology of autotrophic marine dinoflagellates with reference to red water conditions. In: Johnson FH (ed) The luminescence of biological systems. American Association of the Advancement for Science, New York, p $387-413$

Shanks AL (1983) Surface slicks associated with tidally forced internal waves may transport pelagic larvae of benthic invertebrates and fishes shoreward. Mar Ecol Prog Ser 13: $311-315$

Shanks AL (1995) Orientated swimming by megalopae of several eastern North Pacific crab species and its potential role in their onshore migration. J Exp Mar Biol Ecol 186 $1-16$

Shanks AL, Wright WG (1987) Internal-wave-mediated shoreward transport of cyprids, megalopae, and gammarids and correlated longshore differences in the settling rate of intertidal barnacles. J Exp Mar Biol Ecol 114:1-13

Smayda TJ (1997) Harmful algal bloorns: their ecophysiology and general relevance to phytoplankton blooms in the sea. Limnol Oceanogr 42:1137-1153

Tiselius P (1992) Behavior of Acartia tonsa in patchy food environments. Limnol Oceanogr 37:1640-1651

Young CM (1995) Behavior and locomotion during the dispersal phase of larval life. In: McEdward L (ed) Ecology of marine invertebrate larvae. CRC Press, New York, p 249-277

Zeldis JR, Jillett JB (1982) Aggregation of pelagic Mundia gregaria (Fabricius) (Decapoda, Anomura) by coastal fronts and internal waves. J Plankton Res 4:839-857

Submitted: April 2, 1998; Accepted: January 4, 1999

Proofs received from author(s): August 11, 1999 